\title{
Annual to interannual temperature variability in the Caribbean during the Maunder sunspot minimum
}

\author{
Alexandra Haase-Schramm, ${ }^{1}$ F. Böhm, ${ }^{1}$ A. Eisenhauer, ${ }^{1}$ D. Garbe-Schönberg, ${ }^{2}$ \\ W.-C. Dullo, ${ }^{1}$ and J. Reitner ${ }^{3}$ \\ Received 20 January 2005; revised 12 July 2005; accepted 24 August 2005; published 29 November 2005.
}

[1] We reconstruct Caribbean seawater temperatures from sclerosponge $\mathrm{Sr} / \mathrm{Ca}$ ratios using a specimen of Ceratoporella nicholsoni that grew at $20 \mathrm{~m}$ below sea level in a reef cave at Jamaica. We sample the time interval from 1620 to 1745 A.D. with almost monthly resolution. This interval includes the Maunder sunspot minimum, one of the coldest periods of the Little Ice Age. Reconstructed annual temperature amplitudes are on the order of about $1^{\circ} \mathrm{C}$. The mean growth rate calculated from the annual $\mathrm{Sr} / \mathrm{Ca}$ variations corresponds perfectly with U-Th-based growth rates. We find that the interannual climate variability is determined by El NiñoSouthern Oscillation and by a decadal signal, most likely originating from the tropical North Atlantic. On a multidecadal timescale the Maunder Minimum is characterized by a $1^{\circ}-2^{\circ} \mathrm{C}$ cooling and reduced amplitudes of the interannual and decadal temperature variations.

Citation: Haase-Schramm, A., F. Böhm, A. Eisenhauer, D. Garbe-Schönberg, W.-C. Dullo, and J. Reitner (2005), Annual to interannual temperature variability in the Caribbean during the Maunder sunspot minimum, Paleoceanography, 20, PA4015, doi:10.1029/2005PA001137.

\section{Introduction}

[2] During the twentieth century, climate was unusual in the context of the last 1000 years [Mann et al., 1999]. Especially the last decade was unusually warm, including 1998 and 2001-2004 as the warmest 5 years in the instrumental record of global temperature [Hansen et al., 2001; Moberg et al., 2005] (see http://data.giss.nasa.gov/ gistemp/). Climate did always vary throughout the Earth's history, however climate variability can arise from different factors, and there is still a big debate about how much anthropogenic and how much natural changes have played a role during the last century [e.g., Moberg et al., 2005; von Storch et al., 2004]. In order to predict the future climate changes, we still need a better understanding in how the climate system works. This understanding has to be based on observed past variation as a sound foundation for climate modeling. Instrumental meteorological records assess hemispheric and global climate changes over the last 100 to 150 years. More regionally limited data are available back to the early eighteenth century [Jones and Mann, 2004]. Since direct measurements of climate variability are only available about 100 to 200 years back in time, it is necessary to use indirect indicators (proxies) for the reconstruction of earlier climate changes [Jones and Mann, 2004].

[3] Currently, much attention is focused on the climate variability of the tropics. However, tropical paleoclimate

\footnotetext{
${ }^{1}$ Forschungszentrum für Marine Geowissenschaften, IFM-GEOMAR, Kiel, Germany.

${ }^{2}$ Institut für Geowissenschaften, Universität Kiel, Kiel, Germany.

${ }^{3}$ Geobiologie, Geowissenschaftliches Zentrum Göttingen, Göttingen, Germany.
}

Copyright 2005 by the American Geophysical Union. 0883-8305/05/2005PA001137 reconstructions are relatively rare compared to higherlatitude reconstructions [Black et al., 2004] and are mainly based on relatively short coral records. Only few coral records exist that store information about sea surface temperature (SST) back to the seventeenth century, e.g., those of Dunbar et al. [1994], Quinn et al. [1998] and Hendy et al. [2002] in the Pacific Ocean, Zinke et al. [2004] in the Indian Ocean, and Kuhnert et al. [2002] in the Atlantic Ocean. The work of Winter et al. [2000] has focused on Caribbean SST in four 5-year time intervals within the last 300 years.

[4] Climate records from annual to centennial timescales can be derived from sclerosponges. Sclerosponges build a calcareous skeleton similar to reef corals, but with lower growth rates (mostly less than $1.5 \mathrm{~mm} \mathrm{yr}^{-1}$ for Indo-Pacific species and less than $0.5 \mathrm{~mm} \mathrm{yr}^{-1}$ for Caribbean species [Swart et al., 2002; Haase-Schramm et al., 2003; Fallon et al., 2003; Fallon and Guilderson, 2005; Grottoli, 2005]) and extreme longevity (up to several hundred years). Thus sclerosponges can provide data over a long time span. On the other hand, most species do not show annual growth layering, thus dating must be based on radiometric methods. Recent studies have shown that it is possible, with highresolution techniques, to collect intra-annual information from sclerosponge skeletons [Rosenheim et al., 2004, 2005; Swart et al., 2002]. It was further shown that $\mathrm{Sr} / \mathrm{Ca}$ ratios of sclerosponges are a very sensitive temperature proxy [Haase-Schramm et al., 2003; Rosenheim et al., 2004].

[5] In this study we present a 120-year high-resolution (intra-annual) $\mathrm{Sr} / \mathrm{Ca}$ record of the Caribbean sclerosponge Ceratoporella nicholsoni, including the Maunder sunspot minimum (1645-1715 A.D.). The C. nicholsoni specimen used for the reconstruction was collected in 1996 from a reef cave north of Jamaica and is exceptional as it combines a very high average growth rate $\left(0.4 \mathrm{~mm} \mathrm{yr}^{-1}\right)$ 


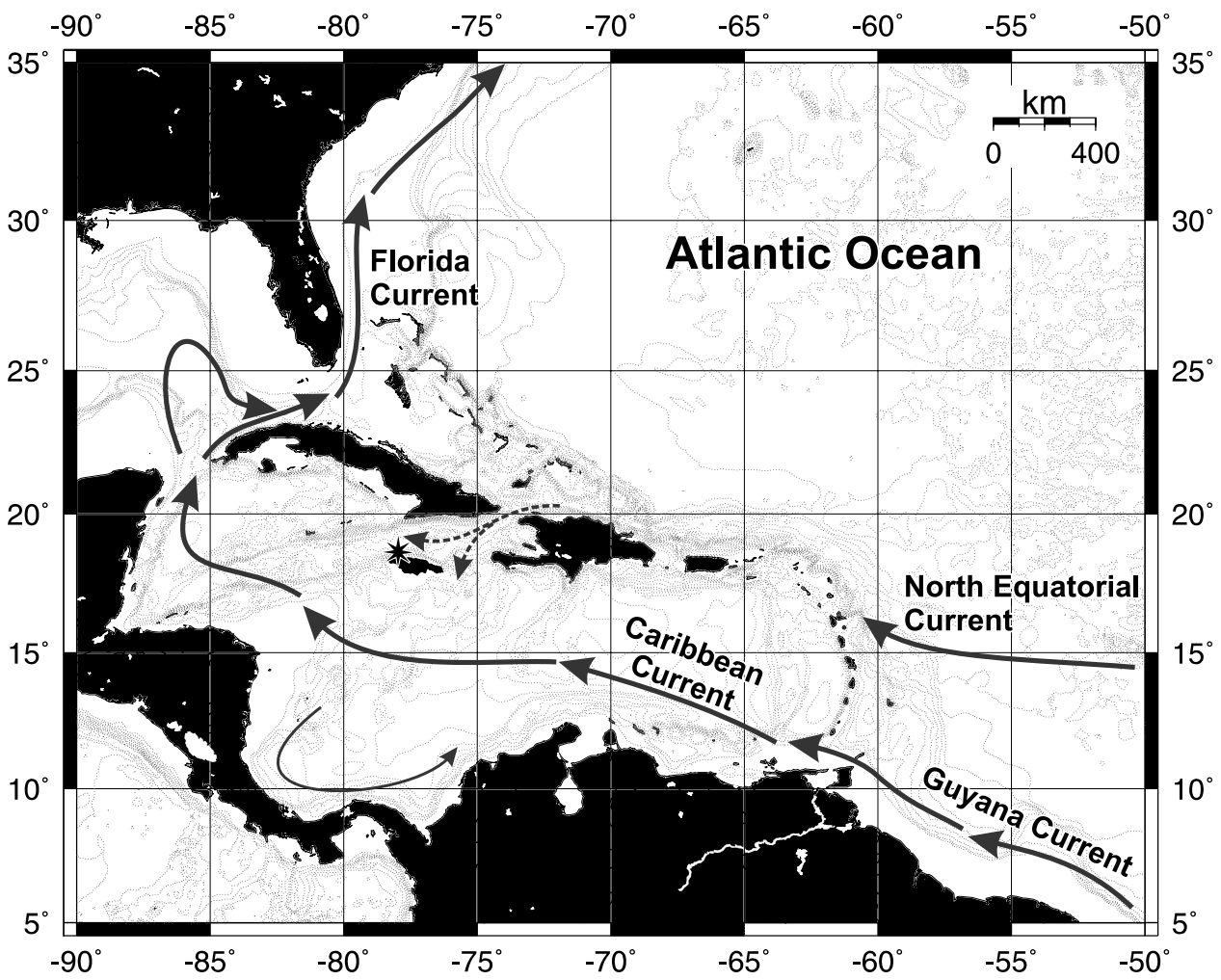

Figure 1. Sampling locality at Jamaica (star) in the Caribbean Sea. Major surface currents are shown. Modified from Haase-Schramm et al. [2003], using data from Gordon [1967], Roberts [1997], and Schmitz and McCartney [1993].

with a 600-year lifespan [Haase-Schramm et al., 2003]. The same specimen has previously been used for the reconstruction of Caribbean mixed layer parameters like preindustrial and anthropogenic carbon isotope variations of total $\mathrm{CO}_{2}$ [Böhm et al., 2002] and the water temperature history using $\mathrm{Sr} / \mathrm{Ca}$ ratios and oxygen isotopes [HaaseSchramm et al., 2003]. Low-resolution sampling combined with radiometric dating in these previous studies provided a framework of decadal to centennial variability in the Caribbean for the last 600 years. It could be shown that the Caribbean mixed layer thickened and at the same time cooled by about $0.5^{\circ} \mathrm{C}$ during the Maunder Minimum [HaaseSchramm et al., 2003]. This prominent period of the Little Ice Age, characterized by a strong cooling in many regions of the Northern Hemisphere [Shindell et al., 2001], was consequently chosen in the current study for highresolution sampling to investigate interannual to decadal temperature variability in the Caribbean.

[6] It is well known from the instrumental record that the Caribbean climate is influenced on interannual and decadal timescales by both the tropical Pacific and the tropical North Atlantic variability [Taylor et al., 2002]. El NiñoSouthern Oscillation (ENSO) has a significant impact on climate in the Caribbean, influencing SST, wind stress, rainfall and the frequency of hurricanes [Enfield and Mayer, 1997; Giannini et al., 2000; Tang and Neelin, 2004]. The impact of ENSO has been observed in tree rings and speleothems in the surroundings of the Caribbean and the Gulf of Mexico [Cleaveland et al., 1992; Lachniet et al.,
2004; Frappier et al., 2002], but ENSO signals are scarcely represented in Caribbean marine proxy time series [Black et al., 2004; Gischler and Oschmann, 2005].

[7] The influence of natural and anthropogenic forcing on the frequency and amplitude of ENSO events and their teleconnections is still not fully understood. D'Arrigo et al. [2005] and Cobb et al. [2003] showed that ENSO variability during the Maunder Minimum was initially very high but later declined to a very low value, a result not fully explained by models of radiative forcing.

[8] With our study we investigate the relative importance of Pacific and Atlantic forcing of Caribbean water temperature during the Maunder Minimum, a period considered crucial for understanding of climate change [D'Arrigo et al., 2005; Rind et al., 2004]. We provide the first subannually resolved marine temperature record for the Maunder Minimum in the northern Caribbean to reconstruct ENSO and other interannual variability during this period of unusual climate.

\section{Material and Methods}

[9] A specimen of the sclerosponge Ceratoporella nicholsoni (Ce96) was collected in spring 1996 at $20 \mathrm{mbsl}$ in a reef cave at Montego Bay, along the north coast of Jamaica $\left(18^{\circ} 28^{\prime} \mathrm{N}, 77^{\circ} 57^{\prime} \mathrm{W}\right)$ (Figure 1). The cave is exposed to the open sea, away from the influence of restricted lagoonal waters. The collection site is located in the Caribbean isothermal surface layer during the whole year. 


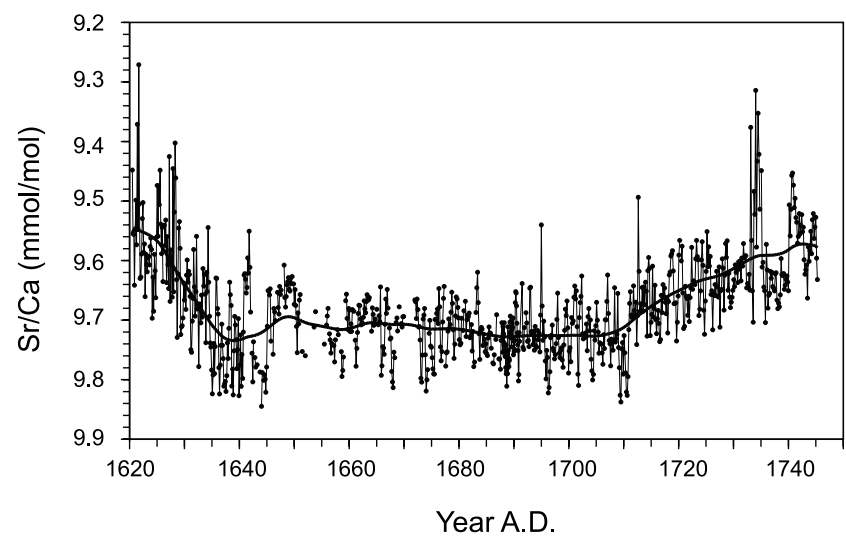

Figure 2. Measured $\mathrm{Sr} / \mathrm{Ca}$ ratios (dots) of the sclerosponge skeleton and long-term trend (line) reconstructed from the first two EOFs of singular spectrum analysis (SSA) (window size 120). Notice the inverse $\mathrm{Sr} / \mathrm{Ca}$ axis.

\subsection{U-Th Dating}

[10] The method for U-Th dating was already published elsewhere [Haase-Schramm et al., 2003]; 0.3 to $1 \mathrm{~g}$ of sponge carbonate was dissolved in warm concentrated $\mathrm{HNO}_{3}$ and spiked with a ${ }^{229} \mathrm{Th}$ and ${ }^{233} \mathrm{U}_{-}{ }^{236} \mathrm{U}$ double spike. The separation of $U$ and $T h$ followed the procedure described by Chen et al. [1986] and Edwards et al. [1987].

\section{2. $\mathrm{Sr} / \mathrm{Ca}$}

[11] Sampling for $\mathrm{Sr} / \mathrm{Ca}$ analysis was carried out using the computer-controlled microdrill (Merchantek Micromill) at the University of Göttingen, similar to the technique described by Swart et al. [2002]. Samples were milled along lines between 0.7 and $2 \mathrm{~mm}$ long, perpendicular to the growth axis. We continuously milled samples in 20 to $50 \mu \mathrm{m}$ steps along a $45 \mathrm{~mm}$ long transect. The drilled lines were $400 \mu \mathrm{m}$ deep. The powder produced by drilling (about 50 to $150 \mu \mathrm{g})$ was directly transferred into the sample tubes (Eppendorf centrifuge tubes) and ready for chemical treatment. The powder was dissolved in $2 \mathrm{~N} \mathrm{HNO}_{3}$. $\mathrm{Sr} / \mathrm{Ca}$ ratios were analyzed using a SPECTRO CIROS CCD SOP ICPAES. For simultaneous measurements of $\mathrm{Sr}$ and $\mathrm{Ca}$ lines of $421 \mathrm{~nm}(\mathrm{Sr})$ and $315 \mathrm{~nm}(\mathrm{Ca})$ were used. External reproducibility from repeated measurements using an in-house sclerosponge standard $\left(\mathrm{Ce} 96-4^{\prime}, \mathrm{n}=16\right)$ and an in-house coral standard (May5A, $\mathrm{n}=20$ ) yielded 0.4 and $0.3 \%$ (double standard deviation, 2SD), respectively. Several samples were measured as duplicates or triplicates. The average external reproducibility determined from these repeated measurements is $0.3 \%$ (double standard error of the mean, 2sem). Internal precision of the sample measurements varies between 0.01 and $0.2 \%$ (relative standard deviation) $(\mathrm{n}=5)$. To account for instrumental drift, our sclerosponge standard (Ce96-4') was measured every 5 samples for reference. The correction factor for each sample is calculated relative to the two bracketing standard measurements, calculated as a linear regression.

\subsection{Time Series Analysis}

[12] Time series analysis (singular spectrum analysis (SSA), multitaper method (MTM), maximum entropy method (MEM)) of the $\mathrm{Sr} / \mathrm{Ca}$ data was carried out with the SSA-MTM toolkit 4.1 [Ghil et al., 2002]. Samples were collected in $50 \mu \mathrm{m}$ steps (measured perpendicular to the growth banding). Intervals with lost samples or with higher sample density were interpolated to a $50-\mu \mathrm{m}$ sample spacing. SSA window sizes were chosen to optimally fit the frequencies of the respective components [Ghil et al., 2002].

\section{Results}

[13] The results of the $\mathrm{U}$ and $\mathrm{Th}$ analysis were published in the work of Haase-Schramm et al. [2003] and only a short summary is provided here. The measured $\delta^{234} U$ ratios lie at $154 \pm 3 \%$. Individual statistical errors (twice the standard error of the mean, 2sem) on the ages vary between 10 and 30 years (one exception of 92 years). The external reproducibility was determined as \pm 20 years (2sem). The whole specimen represents a time interval between 1400 and 1996 A.D. Growth rates were calculated by interpolation with a third-order polynomial. The growth rate of the sponge varies between 0.23 and $0.43 \mathrm{~mm} \mathrm{yr}^{-1}$.

[14] On the basis of the U-Th ages, our sampling transect represents the time period from 1620 to 1745 A.D. The $\mathrm{Sr} / \mathrm{Ca}$ ratios of the sclerosponge vary between 9.3 and $9.8 \mathrm{mmol} \mathrm{mol}^{-1}$, with an average of $9.68 \pm 0.16$ (double standard deviation (2SD)) $\mathrm{mmol} \mathrm{mol}^{-1}$. The $\mathrm{Sr} /$ $\mathrm{Ca}$ ratios show a long-term increase from average values of 9.55 around 1620 A.D. to $9.75 \mathrm{mmol} \mathrm{mol}^{-1}$ at 1640 A.D. (Figure 2, long-term trend reconstructed from the first two EOFs (empirical orthogonal functions) of SSA, window size 120). Between 1640 and 1700 A.D., ratios vary

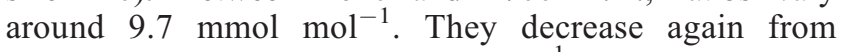
1700 to 1745 A.D. to $9.6 \mathrm{mmol} \mathrm{mol}^{-1}$. In addition to the long-term trend, the $\mathrm{Sr} / \mathrm{Ca}$ ratios show regular high-frequency variations with average amplitudes of 0.1 to $0.2 \mathrm{mmol} \mathrm{mol}^{-1}$ and maximum amplitudes of up to $0.3 \mathrm{mmol} \mathrm{mol}^{-1}$ (Figures 2 and 3).

[15] In order to investigate regular cyclicities and trends, we applied SSA and MTM to the $\mathrm{Sr} / \mathrm{Ca}$ ratios. In the SSA analysis, we find a strong annual signal that explains $19 \%$ of the total variance (represented by EOFs 3-6, window

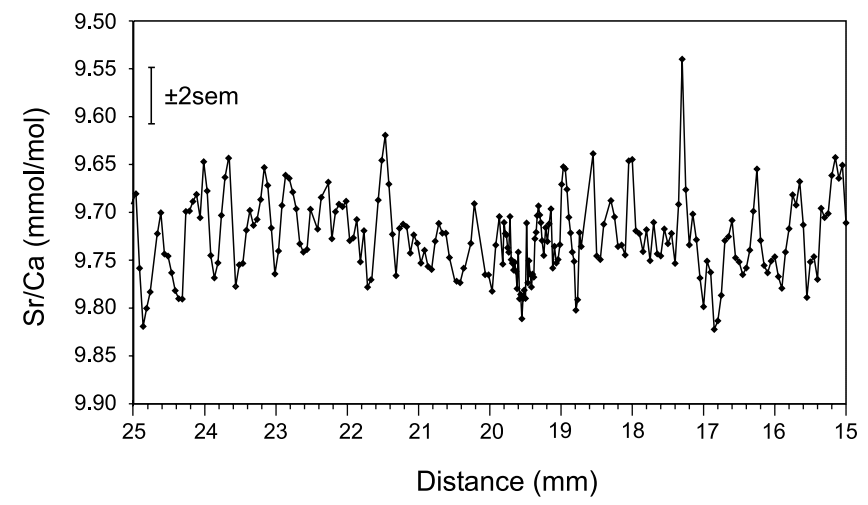

Figure 3. The $10-\mathrm{mm}$ portion of the sclerosponge $\mathrm{Sr} / \mathrm{Ca}$ record demonstrating the regular $\mathrm{Sr} / \mathrm{Ca}$ cycles with average amplitudes between 0.1 and $0.2 \mathrm{mmol} \mathrm{mol}^{-1}$ and maximum amplitude of $0.3 \mathrm{mmol} \mathrm{mol}^{-1}$. 

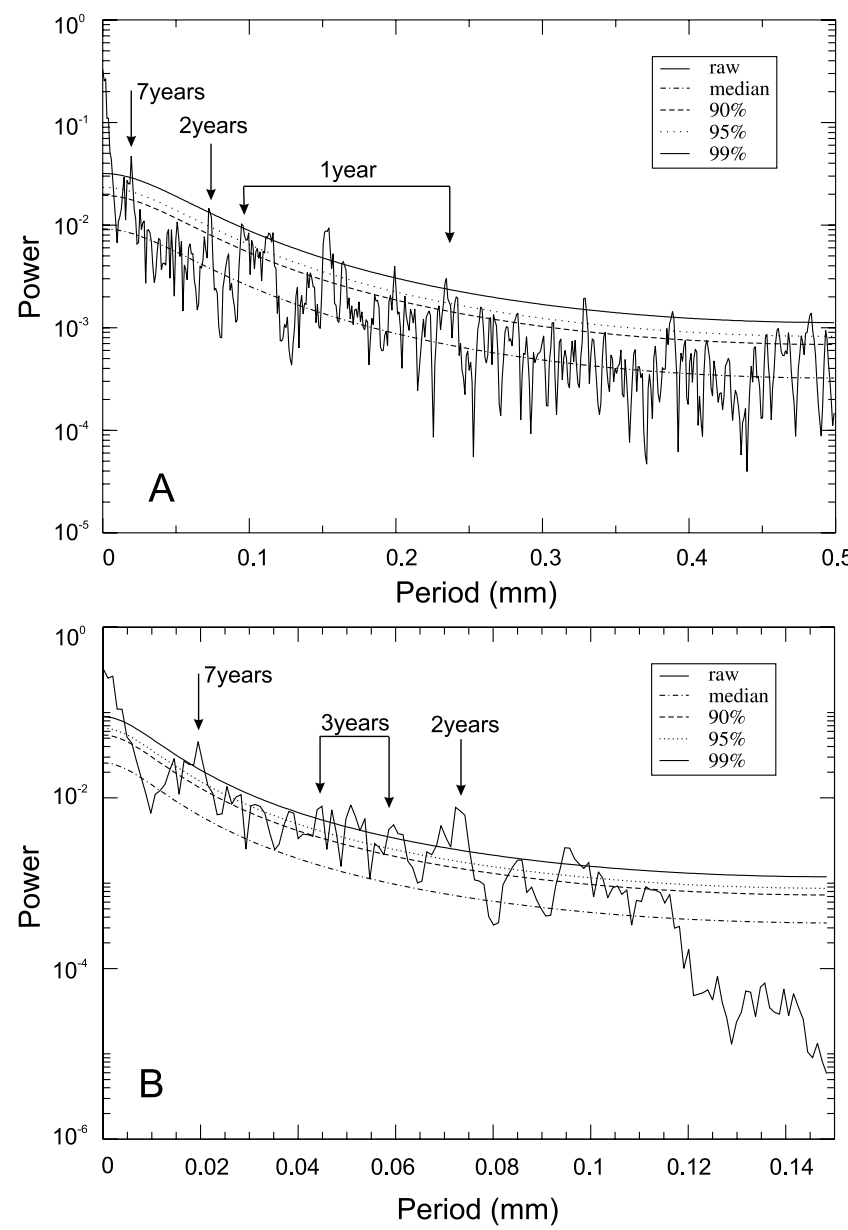

Figure 4. Multitaper method frequency spectrum (a) of the original $\mathrm{Sr} / \mathrm{Ca}$ ratios of the sclerosponge and (b) after filtering the annual $\mathrm{Sr} / \mathrm{Ca}$ signal. Peaks that are above the $99 \%$ significance level are outlined.

size 10). After filtering out the annual signal, we find a 2- to 3-year signal representing 7\% (EOFs 4 to 7) and a 7 -year signal with $14 \%$ of the total variance (EOFs 2 and 3 , window size 45 ). The residual $60 \%$ of the total variance is determined by the trend. All described frequencies produce peaks above the $99 \%$ significance level in the MTM spectrum (Figure 4).

[16] Tuning the time axis to annual $\mathrm{Sr} / \mathrm{Ca}$ cyclicity reveals similar frequencies. However, as annual $\mathrm{Sr} / \mathrm{Ca}$ cycles are not continuously visible, we prefer the more objective timescale calculated from the mean growth rate.

\section{Discussion}

\subsection{Interannual Growth Rate Variations}

[17] Previous work [Haase-Schramm et al., 2003] has shown that the long-term growth rate of specimen Ce96 varied between 230 and $430 \mu \mathrm{m} \mathrm{yr}^{-1}$, based on U-Th ages. The sampling section was selected to lie in a skeletal part with a relatively high average growth rate of $370 \mu \mathrm{m} \mathrm{yr}^{-1}$. The observed $\mathrm{Sr} / \mathrm{Ca}$ cycles are likely representing annual cycles [Swart et al., 2002] (Figure 3). In order to prove this hypothesis, we perform a simple test: If we assume, that each $\mathrm{Sr} / \mathrm{Ca}$ cycle corresponds to 1-year, annual growth rates can be determined by measuring the width of each $\mathrm{Sr} / \mathrm{Ca}$ cycle [Swart et al., 2002]. The resulting growth rates vary between 200 and $600 \mu \mathrm{m} \mathrm{yr}^{-1}$ with a mean of $370 \mu \mathrm{m} \mathrm{yr}^{-1}$ (Figure 5) which is in perfect agreement with the calculated growth rate based on U-Th ages $\left(370 \mu \mathrm{m} \mathrm{yr}^{-1}\right)$. The MTM spectrum of the SSA reconstruction representing the annual signal defines peaks at 550, 330, 310, 250 and $220 \mu \mathrm{m}$ which reflect the range of variation of the annual growth increments, i.e., the short-term variance in the growth rate of the sclerosponge. This variation in growth rate is slightly smaller than determined visually (Figure 5). However, as seen visually, by measuring the width of annual $\mathrm{Sr} / \mathrm{Ca}$ cycles, only $7 \%$ of all cycles show growth rates greater than $500 \mu \mathrm{m} \mathrm{yr}^{-1}$, which is insufficient to produce a significant peak in the MTM spectrum. Thus SSA and visual determination are in good agreement and define the growth rate variation between 200 and $600 \mu \mathrm{m} \mathrm{yr}^{-1}$.

[18] In summary, our results show, first, that the observed variations in $\mathrm{Sr} / \mathrm{Ca}$ ratios really represent annual cycles and, second, that the seasonal $\mathrm{Sr} / \mathrm{Ca}$ variations can be used to obtain annual growth rates. Third, it demonstrates the reliability of our U-Th ages and U-Th-based growth rates. With that we reproduce the results of Swart et al. [2002]. This opens the possibility to create annually resolved timescales for proxy reconstructions with sclerosponges.

\subsection{Annual Temperature Variations}

[19] The sclerosponge of this study (Jamaica, $20 \mathrm{mbsl}$ ) shows annual $\mathrm{Sr} / \mathrm{Ca}$ variations on the order of 0.1 to $0.2 \mathrm{mmol} \mathrm{mol}^{-1}$ in the time period between 1620 and 1745 A.D. (Figures 2 and 3). These variations are relatively small compared to the study of Rosenheim et al. [2004], who find recent annual $\mathrm{Sr} / \mathrm{Ca}$ variations for the same species in Jamaica in $25 \mathrm{~m}$ water depth of about $0.4 \mathrm{mmol} \mathrm{mol}^{-1}$.

[20] For the conversion of $\mathrm{Sr} / \mathrm{Ca}$ to temperature, we use the $\mathrm{Sr} / \mathrm{Ca}$ temperature sensitivity of Rosenheim et al. [2004] of $-0.1 \mathrm{mmol} \mathrm{mol}^{-1} \mathrm{~K}^{-1}$, which is in good agreement with our previously published temperature sensitivity [HaaseSchramm et al., 2003]. On the basis of this, we find in our

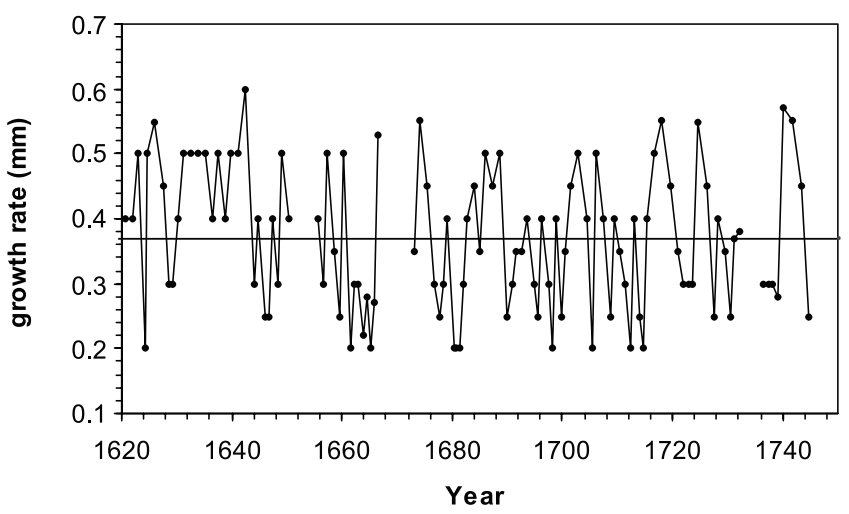

Figure 5. Annual growth rate calculated from the $\mathrm{Sr} / \mathrm{Ca}$ data of the sclerosponge, assuming that each $\mathrm{Sr} / \mathrm{Ca}$ cycle corresponds to 1 year. Horizontal line represents the mean growth rate. 


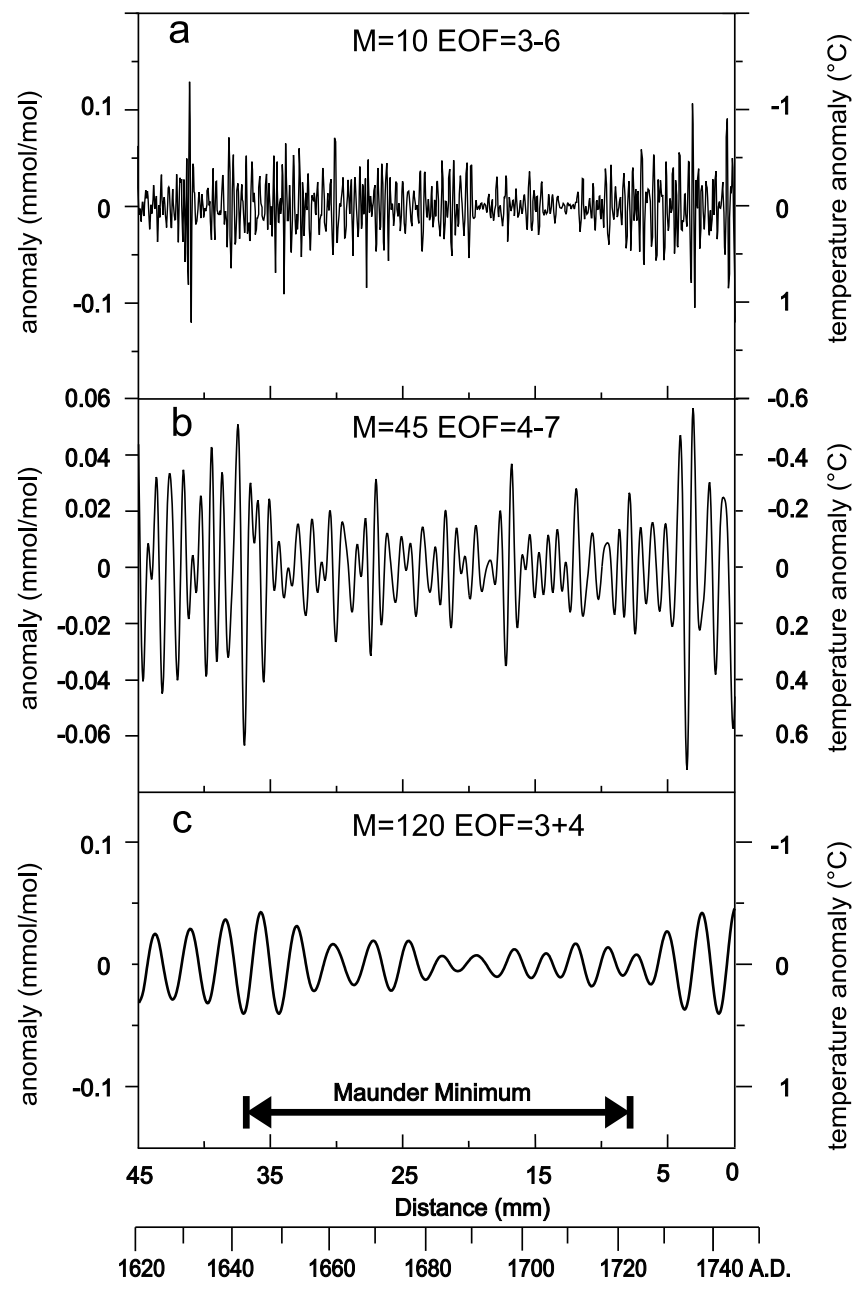

Figure 6. SSA reconstruction of the (a) annual $\mathrm{Sr} / \mathrm{Ca}$ signal, (b) 2- to 3-year $\mathrm{Sr} / \mathrm{Ca}$ signal, and (c) 7-year $\mathrm{Sr} / \mathrm{Ca}$ signal. Window sizes $(\mathrm{M})$ and numbers of the empirical orthogonal functions (EOFs) are shown in Figures 6a-6c. Temperature anomalies are calculated from the $\mathrm{Sr} / \mathrm{Ca}$

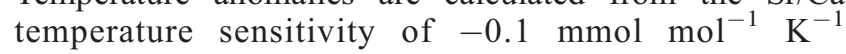
[Rosenheim et al., 2004].

record annual temperature amplitudes of $1^{\circ}$ to $2^{\circ} \mathrm{C}$ and in exceptional cases up to $3^{\circ} \mathrm{C}$. Many of the observed amplitudes do not exceed $1^{\circ} \mathrm{C}$. The SSA reconstruction of the annual signal shows an average annual temperature amplitude of $1^{\circ} \mathrm{C}$ (Figure 6a, window size of 10, EOFs 3-6). Only few events with a higher amplitude of up to $2^{\circ} \mathrm{C}$ appear in the reconstruction at about 1630, 1735 and 1745 A.D.

[21] The recent seasonal temperature variation at our collection site (Montego Bay) was about $3{ }^{\circ} \mathrm{C}$ during the late twentieth century [Levitus and Boyer, 1994], which should cause variations in $\mathrm{Sr} / \mathrm{Ca}$ ratios of $0.3 \mathrm{mmol} \mathrm{mol} \mathrm{m}^{-1}$ [Rosenheim et al., 2004]. Of course, annual temperature amplitudes may have changed since the seventeenth and eighteenth century. However, Winter et al. [2000] found no significant change in annual $\delta^{18} \mathrm{O}$ amplitudes in corals from the eastern Caribbean, comparing a 5 -year slice of the late
Maunder Minimum (LMM) with the 1980s. Watanabe et al. [2001] found only a 20\% reduction of annual LMM temperature variations using $\mathrm{Mg} / \mathrm{Ca}$ ratios in the same corals. It is therefore more likely that the smaller amplitudes of our data compared to the Rosenheim et al. [2004] data are due to the different sampling techniques. Rosenheim et al. [2004] used a laser ablation ICP-MS technique. Although we drilled samples of similar width (about 20 to $50 \mu \mathrm{m}$ ), the depths of our sampling lines $(400 \mu \mathrm{m})$ could have led to some time averaging, smoothing the real temperature amplitudes. This effect has also been observed in corals [Leder et al., 1996; Quinn et al., 1996]. Intraspecific variability can be ruled out because the $\mathrm{Sr} / \mathrm{Ca}$-temperature calibration includes different individuals from different locations [Haase-Schramm et al., 2003; Rosenheim et al., 2004]. Different temperature amplitudes at the sampling site of Rosenheim et al. [2004] and our site can be neglected. Both sites are located in reef caves of similar water depth (20$25 \mathrm{~m}$ ) at the north coast of Jamaica and experienced very similar climatic conditions [Levitus and Boyer, 1994].

\subsection{Interannual Variations}

[22] There are a number of publications that are concerned with climate variability in the Caribbean and its connection to Pacific or Atlantic variations. For example, Enfield and Mayer [1997], Giannini et al. [2001], and Taylor et al. [2002] find relationships between interannual climate changes in the Caribbean and ENSO. According to Enfield and Mayer [1997] ENSO is the dominant mode of interannual temperature variability in the Caribbean. George and Saunders [2001] find NAO-linked variations in the Caribbean. Decadal variations in the Tropical and Subtropical North Atlantic are determined by Andreoli and Kayano [2004] and are connected to the NAO index by Melice and Servain [2003] and Kuhnert et al. [2002].

[23] Our observed 2- to 3-year signal in the Caribbean sponge lies within the frequency band of ENSO. The reconstruction of this signal is shown in Figure 6b. The temperature amplitude of the reconstructed ENSO signal in the Caribbean sclerosponge (early seventeenth to mid eighteenth century) (Figure 6b) is similar to recent ENSO temperature amplitudes in the Caribbean, reconstructed from the Kaplan SSTA data set for $17.5^{\circ} \mathrm{N}, 77.5^{\circ} \mathrm{W}$ for the mid nineteenth to the late twentieth century [Kaplan et al., 1998; Reynolds and Smith, 1994]. This implies that ENSO variability has not dramatically changed between about 400 years ago and today and supports the suggestion of Jones and Mann [2004] that El Niño was relatively constant in the past centuries. On the other hand, in the ENSO reconstruction of the sclerosponge, the temperature amplitudes vary with time: before 1650 A.D. and after 1730 A.D. amplitudes were higher than in between (Figure 6b). The temperature excursions around 1730 and 1740 A.D. coincide with time intervals of strong to very strong El Niño events at 1720, 1728 and 1736 A.D. [Quinn and Neal, 1992]. The time interval with relatively small temperature amplitudes corresponds to the Maunder sunspot minimum. This is similar to the results of Dunbar et al. [1994] who found a 2- to 3-year signal in a Galapagos corals after but not during the Maunder 
Minimum. D'Arrigo et al. [2005] also found decreasing ENSO variability during the Maunder Minimum in an American tree ring reconstruction in agreement with the Pacific coral record of Cobb et al. [2003]. The strong ENSO amplitude around 1640 A.D. coincides with large volcanic eruptions of 1640/41 in Japan and on the Philippines [Briffa et al., 1998, 2004]. So, ENSO variability in our record appears to be associated with solar irradiance variations and possibly with large volcanic eruptions [Mann et al., 2005].

[24] The smoothing effect observed in the annual signal may also slightly influence the interannual temperature records. However, to generate the observed trends in the interannual record would require regular growth rate variations, which are not observed (Figure 5).

\subsection{Decadal Variations}

[25] Besides the observed 2- to 3-year ENSO signal, there is a strong 7-year signal in the sclerosponge record of this study. While the ENSO signal (2-3 years) explains $7 \%$ of the total variance, the 7 -year signal explains $14 \%$. The question arises, if the observed 7-year signal is also caused by ENSO or if it is connected to another mechanism, for example the decadal SST variability in the tropical North Atlantic (TNA) with a periodicity on the order of 8-14 years [Andreoli and Kayano, 2004; Melice and Servain, 2003; Metha and Delworth, 1995], or the decadal NAO band [Kuhnert et al., 2002].

[26] Commonly the ENSO periodicity lies in a range of 1 to 5 years with spectral peaks at 2 to 4 years [Quinn and Neal, 1992]. Thus the observed 7-year signal in the sclerosponge is a marginal case. It is intermediate and could either be put at the low-frequency end of the ENSO band or at the high-frequency end of the Atlantic decadal band.

[27] In the NINO3 SST record [Kaplan et al., 1998; Reynolds and Smith, 1994] 2-4 years define the dominating ENSO period ( $\sim 60 \%$ of the total variance), while 6-year periods are less important ( $20 \%)$. In our sponge record, the 7-year period has a higher variance than the 2- to 3-year period. It is possible that during the seventeenth to eighteenth century ENSO was dominated by low frequencies. However, we conservatively expect a similar pattern of high and low frequencies in the NINO3 record and the Caribbean sclerosponge record. Thus we conclude that the 7-year period is likely a part of the decadal tropical North Atlantic signal and not connected to ENSO.

[28] If we compare our data with the Kaplan SSTA record for the Caribbean site for the last 150 years, the Kaplan SSTA record shows a strong ENSO signal (2-6 years) that explains about $21 \%$ and a decadal signal (10-12 years) that explains about $11 \%$ of the total variance (SSA, EOFs 5 to 10 and EOFs 3 and 4, respectively, window size 200). Consequently, the Kaplan record shows a ratio between interannual and decadal signal of 2:1 for the Caribbean. In our sclerosponge record, the ratio between interannual (23 years) and decadal (7 years) variance is 1:2. Although the two ratios appear different, they are in the same order of magnitude. It is possible, that the interannual signal in our record is underrepresented relative to the decadal signal. For the calculation of the periodicity we use the average growth rate of $370 \mu \mathrm{m} \mathrm{yr}^{-1}$. Since the real growth rate is varying between 230 and $550 \mu \mathrm{m} \mathrm{yr}^{-1}$, it is possible that a certain part of the interannual signal is falsely included in the annual signal in the SSA, which would result in an apparently less strong or frequent interannual signal than it really is. To test the effect of variable growth rates on the reconstructed interannual signal we tuned the time axis to annual $\mathrm{Sr} / \mathrm{Ca}$ cyclicity and found similar amplitudes and frequencies as in the analysis based on a constant growth rate. We conclude that no major changes occurred in the ratio between annual and decadal variability in the Caribbean from the seventeenth to the twentieth century.

[29] In summary, we find similar ENSO temperature amplitudes and similar interannual to decadal amplitude ratios during the early seventeenth to mid eighteenth century and during the nineteenth and twentieth century.

[30] In the SSA reconstruction of the 7-year signal (EOFs 3 and 4, window size of 120) (Figure 6c) the strongest amplitudes occur in the mid seventeenth and in the mid eighteenth century, that is, before and after the Maunder sunspot minimum. Thus not only the ENSO signal, but also the decadal signal was reduced during the Maunder Minimum. This supports the observation, that although the global response to solar irradiance is relatively small, regional response can be larger [Shindell et al., 2001]. The minimum in solar irradiance apparently had an influence on the temperature amplitudes of the ENSO and decadal signals.

[31] The interannual and decadal climate variability in the Caribbean has been investigated by several authors. Three independent driving forces (which in turn can interact) have a significant influence on the Caribbean climate variability on these timescales: first, the ENSO, which seems to be the major mode; second, the decadal tropical North Atlantic variability; and, third, the NAO [Enfield and Mayer, 1997; Giannini et al., 2000, 2001; Stephenson and Chen, 2004; Taylor et al., 2002]. For the Caribbean we find between the early seventeenth and mid eighteenth century similar indications for ENSO-related temperature variability and for a decadal mode, comparable to the decadal tropical North Atlantic mode. Thus we suggest that the climate variability and its major driving forces 400 years ago were the same as today.

\section{Summary and Conclusion}

[32] This study presents the first proxy-based temperature reconstruction for the Caribbean water temperature for a 120-year time period between 1620 and 1745 A.D. during the Little Ice Age with an almost monthly resolution. With the high-resolution sampling method we are able to resolve intra-annual $\mathrm{Sr} / \mathrm{Ca}$ variations in the sclerosponge Ceratoporella nicholsoni from the Caribbean. On the basis of the $\mathrm{Sr} / \mathrm{Ca}$ cycles, which reflect annual temperature cycles, we have determined interannual growth rates that vary between 200 and $550 \mu \mathrm{m} \mathrm{yr}^{-1}$. In the long term, the mean growth rate based on the $\mathrm{Sr} / \mathrm{Ca}$ cycles agrees perfectly with the growth rate determined with U-Th ages $\left(370 \mu \mathrm{m} \mathrm{yr}^{-1}\right)$.

[33] Singular Spectrum Analysis shows that the annual signal explains $19 \%$, the ENSO signal $7 \%$ and the decadal signal $14 \%$ of the total variance. The annual $\mathrm{Sr} / \mathrm{Ca}$ cycles 
are direct indicators for temperature variations, with average annual temperature amplitudes on the order of $1^{\circ} \mathrm{C}$. We find that ENSO temperature variabilities and interannual to decadal amplitude ratios during the early seventeenth to mid eighteenth century were similar as in the nineteenth to twentieth century. However, during the Maunder sunspot minimum, both ENSO and decadal signals were reduced, which implies that solar forcing also had a strong influence on the Caribbean climate.

[34] In our work we show that during the studied time interval in the Little Ice Age (1620 to 1745 A.D.) one leading factor in the interannual climate variability is related to ENSO, while the decadal variability is likely connected to the tropical North Atlantic. This would suggest that the major factors that determine the climate variability in the Caribbean have not changed over the past 400 years.

[35] Acknowledgments. We thank Gerhard Wörner, who provided the possibility of using the Microdrill facility in the University Göttingen. Thanks to Karin Kissling for help with the ICP-AES measurements. Financial support to A.H.S. and A.E. was provided by the "Deutsche Forschungsgemeinschaft" (Ei272/10-2). The critical reviews of Andrea Grottoli, an anonymous referee, and the editor Larry Peterson are gratefully acknowledged.

\section{References}

Andreoli, R. V., and M. T. Kayano (2004), Multiscale variability of the sea surface temperature in the tropical Atlantic, J. Geophys. Res., 109, C05009, doi:10.1029/2003JC002220.

Black, D. E., R. C. Thunell, A. Kaplan, L. C. Peterson, and E. J. Tappa (2004), A 2000-year record of Caribbean and tropical North Atlantic hydrographic variability, Paleoceanography, 19, PA2022, doi:10.1029/2003PA000982.

Böhm, F., A. Haase-Schramm, A. Eisenhauer, and W.-C. Dullo (2002), Evidence for preindustrial variations in the marine surface water carbonate system from coralline sponges, Geochem. Geophys. Geosyst., 3(3), 1019, doi: $10.1029 / 2001 \mathrm{GC} 000264$.

Briffa, K. R., P. D. Jones, F. H. Schweingruber, and T. J. Osborn (1998), Influence of volcanic eruptions on Northern Hemisphere summer temperature over the past 600 years, Nature, 393, 450-455.

Briffa, K. R., T. J. Osborn, and F. H. Schweingruber (2004), Large-scale temperature inferences from tree rings: A review, Global Planet. Change, 40, $11-26$.

Chen, J. H., L. Edwards, and G. J. Wasserburg (1986), ${ }^{238} \mathrm{U},{ }^{234} \mathrm{U}$ and ${ }^{232} \mathrm{Th}$ in seawater, Earth Planet. Sci. Lett., 80, 241-251.

Cleaveland, M. K., E. R. Cook, and D. W. Stahle (1992), Secular variability of the Southern Oscillation detected in tree-ring data from Mexico and the southern United States, in Paleoclimatic Aspects of ENSO, edited by H. Diaz and V. Markgraf, pp. 271-291, Cambridge Univ. Press, New York.

Cobb, K. M., C. D. Charles, H. Cheng, and R. L. Edwards (2003), El Niño/Southern Oscillation and tropical Pacific climate during the last millennium, Nature, 424, 271-276.

D’Arrigo, R., E. R. Cook, R. J. Wilson, R. Allan, and M. E. Mann (2005), On the variability of ENSO over the past six centuries, Geophys. Res. Lett., 32, L03711, doi:10.1029/ 2004GL022055.

Dunbar, R. B., G. M. Wellington, M. W. Colgan, and P. W. Glynn (1994), Eastern Pacific sea surface temperature since 1600 A.D.: The $\delta^{18} \mathrm{O}$ record of climate variability in Galápagos corals, Paleoceanography, 9, 291-315.

Edwards, R. L., J. H. Chen, T. L. Ku, and G. J. Wasserburg (1987), Precise timing of the last interglacial period from mass spectrometric determination of thorium-230 in corals, Science, 236, 1547-1553.

Enfield, D. B., and D. A. Mayer (1997), Tropical Atlantic sea surface temperature variability and its relation to El Niño-Southern Oscillation, J. Geophys. Res., 102, 929-945.
Fallon, S. J., and T. P. Guilderson (2005), Extracting growth rates from the non-laminated coralline sponge Astrosclera willeyana using "bomb" radiocarbon, in Limnology and Oceanography: Methods, in press.

Fallon, S. J., T. P. Guilderson, and K. Caldeira (2003), Carbon isotope constraints on vertical mixing and air-sea $\mathrm{CO}_{2}$ exchange, Geophys. Res. Lett., 30(24), 2289, doi:10.1029/ 2003GL018049.

Frappier, A., D. Sahagian, L. A. Gonzalez, and S. J. Carpenter (2002), El Niño events recorded by stalagmite carbon isotopes, Science, $298,565$.

George, S. E., and M. A. Saunders (2001), North Atlantic oscillation impact on tropical north Atlantic winter atmospheric variability, Geophys. Res. Lett., 28, 1015-1018.

Ghil, M., et al. (2002), Advanced spectral methods for climatic time series, Rev. Geophys., 40(1), 1003, doi:10.1029/2000RG000092.

Giannini, A., Y. Kushnir, and M. A. Cane (2000), Interannual variability of Caribbean rainfall, ENSO, and the Atlantic Ocean, J. Clim., 13, 297-311.

Giannini, A., J. C. H. Chiang, M. A. Cane, Y. Kushnir, and R. Seager (2001), The ENSO teleconnection to the tropical Atlantic Ocean: Contributions of the remote and local SSTs to rainfall variability in the tropical Americas, J. Clim., 14, 4530-4544.

Gischler, E., and W. Oschmann (2005), Historical climate variation in Belize (Central America) as recorded in Scleractinian coral skeletons, Palaios, 20, 159-174.

Gordon, A. L. (1967), Circulation of the Caribbean Sea, J. Geophys. Res., 72, 6207-6223.

Grottoli, A. G. (2005), Monthly resolved stable oxygen isotope record in a Palauan sclerosponge Acanthochaetetes wellsi for the period of 1977-2001, in Proceedings of the 10th International Coral Reef Symposium, in press.

Haase-Schramm, A., F. Böhm, A. Eisenhauer, W.-C. Dullo, M. M. Joachimski, B. Hansen, and J. Reitner (2003), $\mathrm{Sr} / \mathrm{Ca}$ ratios and oxygen isotopes from sclerosponges: Temperature history of the Caribbean mixed layer and thermocline during the Little Ice Age, Paleoceanography, 18(3), 1073, doi:10.1029/2002PA000830.

Hansen, J. E., R. Ruedy, M. Sato, M. Imhoff, W. Lawrence, D. Easterling, T. Peterson, and T. Karl (2001), A closer look at United States and global surface temperature change, J. Geophys. Res., 106, 23,947-23,963.

Hendy, E. J., M. K. Gagan, C. A. Alibert, M. T. McCulloch, J. M. Lough, and P. J. Isdale
(2002), Abrupt decrease in tropical Pacific sea surface salinity at end of Little Ice Age, Science, 295, 1511-1514.

Jones, P. D., and M. E. Mann (2004), Climate over the past millennia, Rev. Geophys., 42 RG2002, doi:10.1029/2003RG000143.

Kaplan, A., M. A. Cane, Y. Kushnir, A. C. Clement, M. B. Blumenthal, and B. Rajagopalan (1998), Analysis of global sea surface temperatures 1856-1991, J. Geophys. Res., 103, $18,567-18,589$.

Kuhnert, H. P., J. B. Schnetger, and G. Wefer (2002), Sea-surface temperature variability in the 16th century at Bermuda inferred from coral records, Palaeogeogr. Palaeoclimatol. Palaeoecol., 179, 159-171.

Lachniet, M. S., S. J. Burns, D. R. Piperno, Y. Asmerom, V. J. Polyak, C. M. Moy, and K. Christenson (2004), A 1500-year El Niño/ Southern Oscillation and rainfall history for the Isthmus of Panama from speleothem calcite, J. Geophys. Res., 109, D20117, doi:10.1029/2004JD004694.

Leder, J. J., P. K. Swart, A. M. Szmant, and R. E. Dodge (1996), The origin of variations in the isotopic record of scleractinian corals: I. Oxygen, Geochim. Cosmochim. Acta, 60, 28572870

Levitus, S., and T. Boyer (1994), World Ocean Atlas 1994, vol. 4, Temperature, NOAA Atlas NESDIS 4, 129 pp., Natl. Oceanic and Atmos. Admin., Silver Spring, Md.

Mann, M. E., R. S. Bradley, and M. K. Hughes (1999), Northern Hemisphere temperatures during the past millennium: Inferences, uncertainties and limitations, Geophys. Res. Lett., 26, 759-762.

Mann, M. E., M. A. Cane, S. E. Zebiak, and A. Clement (2005), Volcanic and solar forcing of the tropical Pacific over the past 1000 years, J. Clim., 18, 417-456.

Melice, J.-L., and J. Servain (2003), The tropical Atlantic meridional SST gradient index and its relationships with the SOI, NAO and Southern Ocean, Clim. Dyn., 20, 447-464.

Metha, V. M., and T. Delworth (1995), Decadal variability of the tropical Atlantic Ocean sea surface temperature in shipboard measurements in a global ocean-atmosphere model, J. Clim., 8, 172-190.

Moberg, A., D. M. Sonechkin, K. Holgren, N. M. Datsenko, and W. Karlén (2005), Highly variable Northern Hemisphere temperatures reconstructed from low- and high-resolution proxy data, Nature, 433, 613-617.

Quinn, T. M., F. W. Taylor, T. J. Crowley, and S.M. Link (1996), Evaluation of sampling 
resolution in coral stable isotope records: A case study using records from New Caledonia and Tarawa, Paleoceanography, 11, 529-542.

Quinn, T. M., T. J. Crowley, F. W. Taylor, C. Henin, P. Joannot, and Y. Join (1998), A multicentury stable isotope record from a New Caledonia coral: Interannual and decadal sea surface temperature in the southwest Pacific since 1657 A. D., Paleoceanography, $13,412-426$.

Quinn, W. H., and V. T. Neal (1992), The historical record of El Nino events, in Climate Since $A D$ 1500, edited by P. D. Jones, pp. 623-648, Routledge, Boca Raton, Fla.

Reynolds, R. W., and T. M. Smith (1994), Improved global sea surface temperature analysis using optimum interpolation, J. Clim., 7, 929948.

Rind, D., D. Shindell, J. Perlwitz, J. Lerner, P. Lonergan, J. Lean, and C. McLinden (2004), The relative importance of solar and anthropogenic forcing of climate change between the Maunder Minimum and the present, J. Clim., 17, 906-929.

Roberts, C. M. (1997), Connectivity and management of Caribbean coral reefs, Science, 278, 1454-1457.

Rosenheim, B. E., P. K. Swart, S. R. Thorrold, P. Willenz, L. Berry, and C. Latkoczy (2004), High-resolution $\mathrm{Sr} / \mathrm{Ca}$ records in sclerosponges calibrated to temperature in situ, Geology, 32(2), 145-148.

Rosenheim, B. E., P. K. Swart, S. R. Thorrold, A. Eisenhauer, and P. Willenz (2005), Salinity change in the subtropical Atlantic: Secular increase and teleconnections to the North Atlantic Oscillation, Geophys. Res. Lett., 32, L02603, doi:10.1029/2004GL021499.

Schmitz, W. J., and M. S. McCartney (1993), On the North Atlantic circulation, Rev. Geophys., 31, 29-49.

Shindell, D. T., G. A. Schmidt, M. E. Mann, D. Rind, and A. Waple (2001), Solar forcing of regional climate change during the Maunder Minimum, Science, 294, 2149-2152.

Stephenson, T. S., and A. A. Chen (2004), Analyzing and understanding climate variability in the Caribbean islands, paper presented at 13th Symposium on Global Change and Climate Variations, Am. Meteorol. Soc., Seattle, Wash.

Swart, P. K., S. Thorrold, B. Rosenheim, A. Eisenhauer, C. G. A. Harrison, M. Grammer, and C. Latkoczy (2002), Intra-annual variation in the stable oxygen and carbon and trace element composition of Sclerosponges, Paleoceanography, 17(3), 1045, doi:10.1029/ 2000PA000622.

Tang, B. H., and J. D. Neelin (2004), ENSO influence on Atlantic hurricanes via tropospheric warming, Geophys. Res. Lett., 31, L24204, doi:10.1029/2004GL021072.

Taylor, A. M., D. B. Enfield, and A. A. Chen (2002), Influence of the tropical Atlantic versus the tropical Pacific on Caribbean rainfall, J. Geophys. Res., 107(C9), 3127, doi:10.1029/ 2001JC001097.

von Storch, H., E. Zorita, J. M. Jones, Y. Dimitriev, F. González-Rouco, and S. F. B. Tett (2004),
Reconstructing past climate from noisy data, Science, 306, 679-682.

Watanabe, T., A. Winter, and T. Oba (2001), Seasonal changes in sea surface temperature and salinity during the Little Ice Age in the Caribbean Sea deduced from $\mathrm{Mg} / \mathrm{Ca}$ and ${ }^{18} \mathrm{O} /{ }^{16} \mathrm{O}$ ratios in corals, Mar. Geol., 173, 21-35

Winter, A., H. Ishioroshi, T. Watanabe, and T. Oba (2000), Caribbean sea surface temperatures: Two-to-three degrees cooler than present during the Little Ice Age, Geophys. Res. Lett., 27, 3365-3368.

Zinke, J., W.-C. Dullo, G. A. Heiss, and A. Eisenhauer (2004), ENSO and Indian Ocean subtropical dipole variability is recorded in a coral record off southwest Madagascar for the period 1659 to 1995 , Earth Planet. Sci. Lett. $228,177-194$

F. Böhm, W.-C. Dullo, A. Eisenhauer, and A. Haase-Schramm, Forschungszentrum für Marine Geowissenschaften, IFM-GEOMAR, Wischhofstr. 1-3, D-24148 Kiel, Germany. (fboehm@ifm-geomar.de; ahaase@ifm-geomar. de)

D. Garbe-Schönberg, Institut für Geowissenschaften, Universität Kiel, D-24098 Kiel, Germany.

J. Reitner, Geobiologie, Geowissenschaftliches Zentrum Göttingen, D-37077 Göttingen, Germany. 